\title{
SYNTHESIS OF BARIUM TANNATE FROM EUCALYPTUS BARK AND ITS USE AS A THERMAL STABILIZER FOR POLY(VINYL CHLORIDE)
}

\author{
Hussein Ali Shnawa, ${ }^{\mathrm{a}, *}$ Muhsen Gelap M., ${ }^{\mathrm{a}}$ Dia’a Abed Aldaeem A., ${ }^{\mathrm{a}}$ Ibrahem Kadim \\ A., ${ }^{a}$ Faise Gumaa M., ${ }^{b}$ and Afaf Saleh I. ${ }^{b}$
}

\begin{abstract}
In this work tannin was isolated from the outer bark of the eucalyptus tree, then treated with $\mathrm{Ba}(\mathrm{OH})_{2}$ to synthesize barium tannate (Ba-tan). The derivative was evaluated as a thermal stabilizer for polyvinyl chloride (PVC). PVC was mixed with Ba-tan thermally at four percentages $(0.5$, $1.0,2.0$, and 2.5$) \% \mathrm{w} / \mathrm{w}$. The samples were pressed thermally to films having thickness ranging between 0.25 and $0.30 \mathrm{~mm}$. The effect of Batan was studied by monitoring the weight of samples under iso-thermal conditions at $250^{\circ} \mathrm{C}$. Thermal stability of PVC increased with increasing Ba-tan percent. Samples weight curves also indicated that the additive had been suitably active to increase the resistance of PVC against thermal degradation, where the degradation rates decreased from about $0.21 \% \mathrm{wt} / \mathrm{min}$. at $0.5 \%$ of Ba-tan on PVC to reach to $0.05 \% \mathrm{wt} / \mathrm{min}$. for the $2.5 \%$ treated sample. The ability of Ba-tan to react with and remove $\mathrm{HCl}$ from the system of polymer during thermal conditioning of samples and during the measurement led to this effect. Therefore the present results demonstrate the performance of this derivative as a thermal stabilizer.
\end{abstract}

Key words: Tannin; PVC; Thermal stability; Monitoring sample weight; Thermal stabilizers; Eucalyptus bark

Contact information: a: Polymer Research Center, University of Basrah; b: State Company for Petrochemical Industries, Basrah ,Iraq; *Corresponding author E-mail: hussanqi@yahoo.com

\section{INTRODUCTION}

Tannins are natural phenolic compounds consisting of mixtures from simple phenols (hydrolysable tannins) and polymeric phenols (condensed tannin). They are widely distributed in plants, especially in the bark (Chesworth et al. 1998; Ollis 1961; Ahmed et al. 1989). A characteristic ability of tannin is their strong interaction with proteins and heavy metal ions to form precipitated complexes. Many potential applications of tannins such as astringency, inhibition of enzymatic activity, and antifungal activity are also based on this property. Clarifying the mechanism of tanninprotein or tannin-metals interaction is an important key for understanding the chemical properties of tannin (Kawamoto 1996; Kawamoto et al. 1995). Kawamoto and his coworkers used HPLC to study the tannin-bovine serum albumin co-precipitates. They found that the relative affinity is affected mainly by the number of the galloyl groups in the gallolglucose (tannin) molecule. 
Generally, condensed tannins have strong complexing ability for metal ions such as iron (III) and aluminum (III). Related hydrolysable tannins have been used for the quantitave precipitation of trace metals from their solutions. Yoneda and Nakatsubo (1998) studied the effects of hydroxylation patterns and polymerization degrees of condensed tannins on their aluminum-chelating capacity and they reported that the phenolic hydroxyl groups of the tannins that are essential sites for the chelating with metal ions are mainly o-dihydroxy phenyl tannin groups (Fig. 1) (Chesworth et al. 1998).

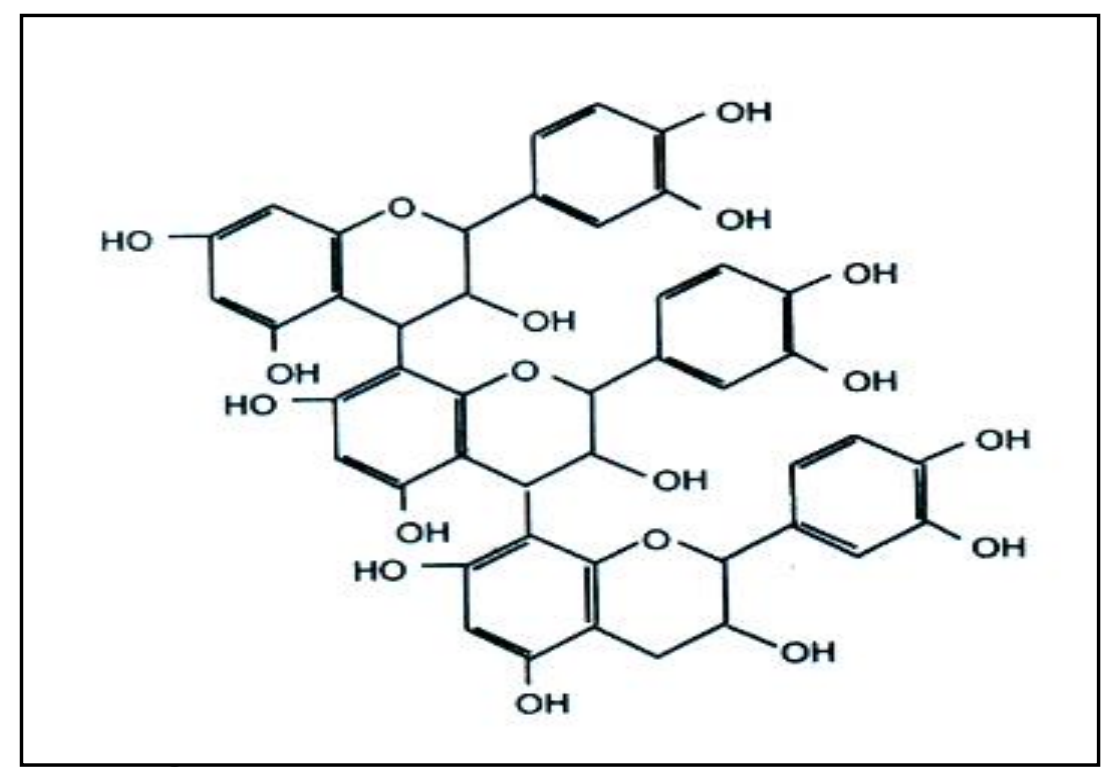

In this paper, the effects and performance of barium-tannin chelate as a thermal stabilizer for PVC was studied.

\section{EXPERIMENTAL}

\section{Materials}

Barium hydroxide was supplied by J. T. Baker, sodium hydroxide was from Gainland Chemical Co., $\mathrm{HCl}$ was from $\mathrm{BDH}$, and dioctyl phthalate (DOP) was a commercial product from National Company of Plastics Industries.

PVC was supplied by State Company for Petrochemical Industries, Basrah, Iraq. It had the follow properties: K-value, 66; volumetric density, $0.45 \mathrm{gm} / \mathrm{cm}^{2}$ (min.); volatiles cont., $0.5 \%$ wt. (max.). These reagents and materials were used without further purification.

\section{Isolation of Tannin}

50 gm of eucalyptus outer bark powder was refluxed with $1 \mathrm{~L}$ of $2 \% \mathrm{NaOH}$ solution for $24 \mathrm{hr}$., the extract was vacuum filtered, the $\mathrm{pH}$ of the tannin solution was adjusted to $\mathrm{pH}$ $=2.5$ with $0.5 \mathrm{~N} \mathrm{HCl}$, then the solids were dried and washed with distilled water . 


\section{Barium-Tannate Synthesis}

The sample (15 g) from tannin was dissolved in $50 \mathrm{~mL}$ water. Clear $\mathrm{Ba}(\mathrm{OH})_{2}$ solution (15 g in distilled water previously filtered) was slightly added with stirring. The addition was continued until the $\mathrm{pH}$ reached 12.5. The mixture kept standing for $24 \mathrm{hr}$. The brown precipitate was filtered and washed with distilled water several times. The weight of barium-tannate was about $15.5 \mathrm{~g}$.

\section{Mixing of Barium-Tannate with PVC}

The mixing process of this derivative with PVC at four percentages $(0.5,1.0,2.0$, and 2.5)\% w/w was carried out by Haake rheocord torque rheometer, with the following procedure: $200 \mathrm{~g}$ of PVC was mixed with barium-tannate at weight ratios (1:199, 2:198, 4:196, and 5:195) Ba.tan:PVC, respectively, and 10\% DOP per weight of PVC handily, then the mixture was put in the mixer chamber operated at $60 \mathrm{rpm}$ for $15 \mathrm{~min}$. at $80{ }^{\circ} \mathrm{C}$, and the heat was raised to $160{ }^{\circ} \mathrm{C}$ with continuous mixing for a further $10 \mathrm{~min}$.

\section{Samples Preparation}

The samples of PVC were sheeted between two plates of thermal- hydraulic press type (F \& R AL - Haddad) for 5 min. under a loading of 5 tons pressure at $180{ }^{\circ} \mathrm{C}$. Then the pressure was raised to 10 tons for another $5 \mathrm{~min}$. The resulting thickness of samples ranged between 0.25 to $0.30 \mathrm{~mm}$.

\section{Infrared Analysis}

A Fourier Transform Infrared Spectrometer type FT-IR-4800S by Shimatzu Co. was used for analysis of functional groups. Spectra of tannin and of barium-tannin chelate were recorded with $\mathrm{KBr}$ powder as pellets.

\section{Thermal Stability Measurements}

Evaluations of the thermal stability of PVC samples were carried out under isothermal conditions at $250{ }^{\circ} \mathrm{C}$ and normal air atmosphere by monitoring the changes that happen in a sample's weight as function to time. The apparatus used in this set of measurements was illustrated by Khalaf et al. (2007): When the oven of this apparatus was heated to temperature $\left(250^{\circ} \mathrm{C}\right)$, a part of the sample approximately $0.05 \mathrm{~g}$ was put in the sample crucible inside the oven, and an electronic balance was used to read the initial weight and also the changes that happen during heating.

\section{RESULTS AND DISCUSSION}

It has been believed that the sites of tannins that interact with metal ions are odihydroxy phenyl units, as shown in the tannin chemical structure (Fig. 1); the isolated hydroxyl groups of other units are not present and seem to be very low in these interactions (Yoned and Nakatsubo 1998). In the complexation of tannin with metal ions, the coordinate bonds between the oxygen of phenolic hydroxyl groups and the metal barium-tannin chelate was synthesized as a co-precipitate complex from reaction of 
tannin with an aqueous solution of barium hydroxide. Figure 2 shows the reaction for synthesis of this complex.

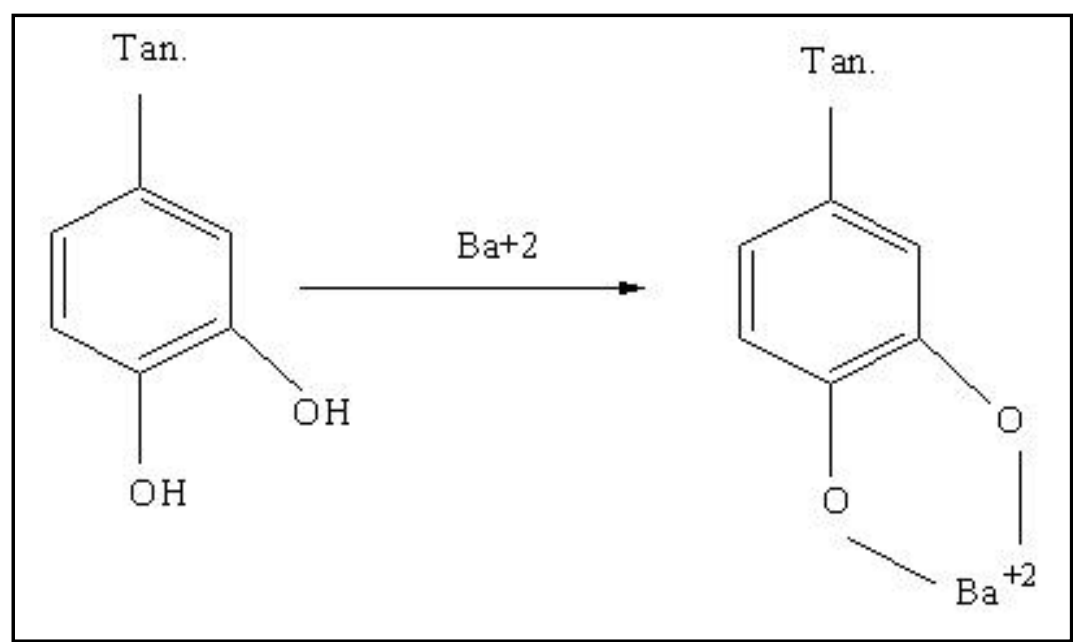

Fig. 2. Reaction of barium tannate synthesis

The chemical structure of this derivative was confirmed by FTIR. Figures 3 and 4 show the FTIR curve of tannin and barium-tannin chelate, respectively. The most interesting peaks in Fig. 4 are at $1400-1450 \mathrm{~cm}^{-1}$ and at $1080 \mathrm{~cm}^{-1}$. Such peaks are reasonably attributed to the C-O bond of barium salt (Rabek 1970), and also these peaks are not found in the spectra of pure tannin, Figs. 3 and 4.

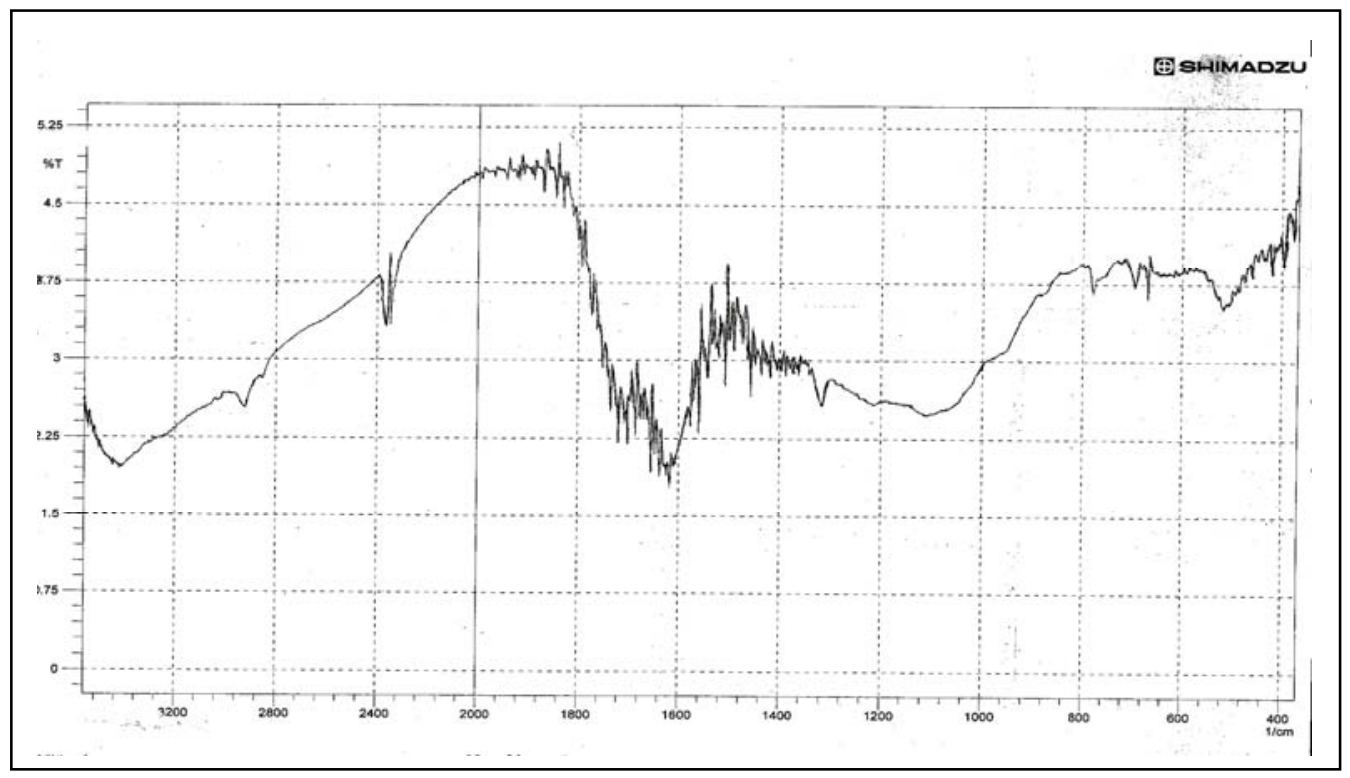

Fig. 3. FTIR curve of pure tannin 


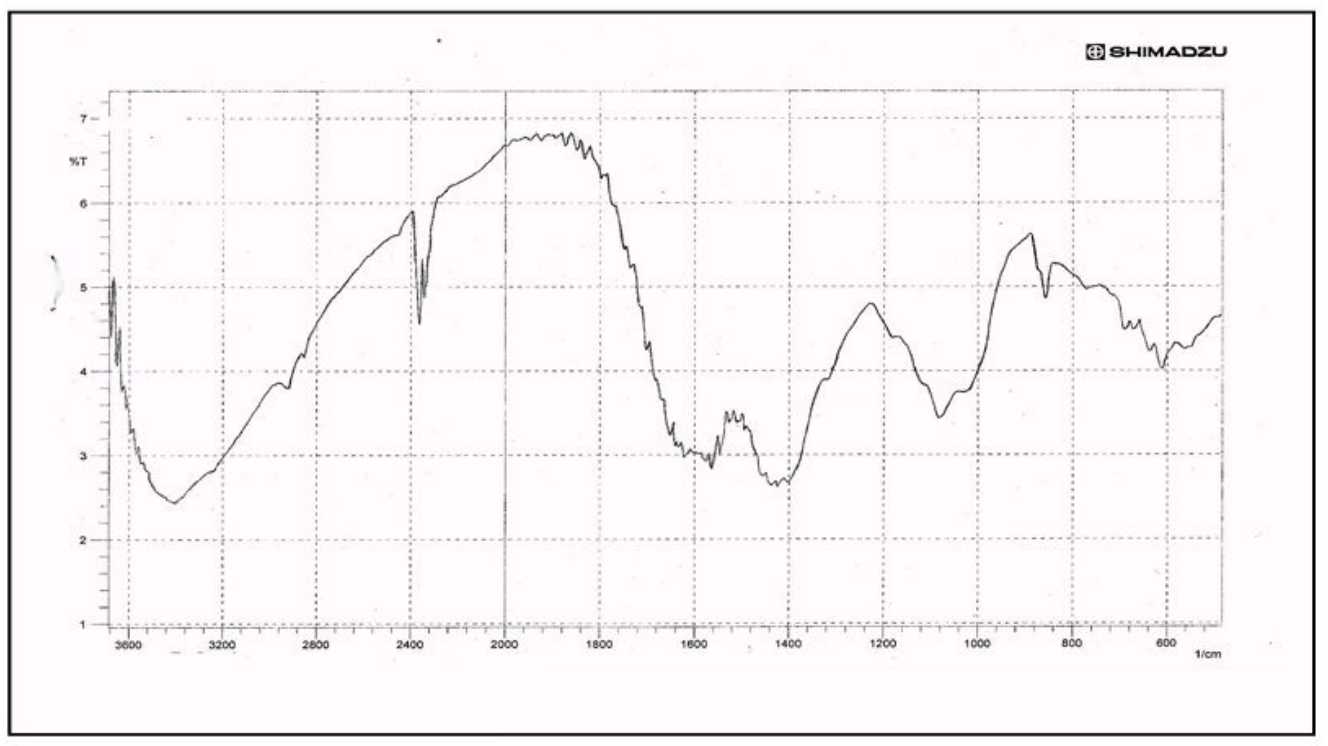

Fig. 4. FTIR curve of barium tannate

Additionally, the peak at about $1300 \mathrm{~cm}^{-1}$ in the FTIR spectrum of pure tannin, Fig. 3, is attributed to the absorption of the aromatic hydroxylic groups. This peak disappeared after the treatment of tannin with barium ion (Fig. 4); the peak was not found due to the formation of chelating salt. It is well known that the deterioration of poly(vinyl chloride) is due primarily to zipper-like elimination of hydrogen chloride, which gives rise to pigmented and easily oxidizable polyene. However, the degradation reaction of PVC is autocatalyzed by $\mathrm{HCl}$ and can occur at temperatures below or near to polymer processing and molding (Owen 1984; Braun and Bezdadea 1986); therefore thermal stabilizers must be added and must have reactivity to remove $\mathrm{HCl}$ from the system. They also can react with irregular groups to form more stable products (Owen 1984; Braun and Bezdadea 1986; Alfred and Raymond 1959).

The thermal stability of PVC in the presence of barium tannate also was studied by monitoring the weight of samples. Results of tests carried out under isothermal conditions are shown in Fig. 5. Samples conditions the Ba-tan additives exhibited greater thermal stability. Resistance of PVC to thermal degradation increased with increase of Ba-tan.

As can be seen, the curves in Fig. 5 show a decreasing rate of decomposition with increase of the salt percentage, whereas it was about $0.21 \% \mathrm{wt} / \mathrm{min}$. at $0.5 \%$ sample, and it decreased to reach to about $0.1 \% \mathrm{wt} / \mathrm{min}$ and $0.05 \% \mathrm{wt} / \mathrm{min}$. for $2.0 \%$ and $2.5 \%$ barium tannate. Some of the sample may be consumed during thermal mixing, and therefore this sample may have not enough time until the starting of degradation reactions. The ability of this derivative to act as a thermal stabilizer comes from reaction with $\mathrm{HCl}$ and its removal to form the polymer system. Figure 6 shows the suggested mechanism for the thermal stabilized effect of this derivative. The product of this action may play another main role to increase the stability of this polymer against to thermal oxidation degradation due to the nature of the phenolic molecule of native tannin. Thus, this derivative has two advantageous effects, thermal stability and antioxidant activity. 


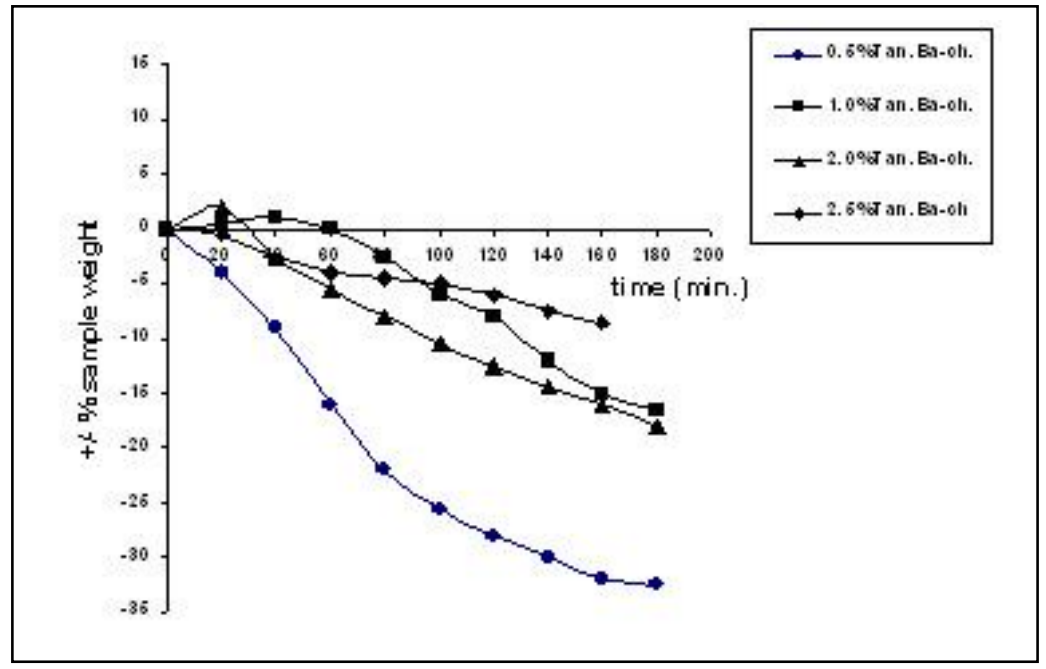

Fig. 5. Thermograms of pvc with tannin-barium chelate degradation at $250^{\circ} \mathrm{C}$

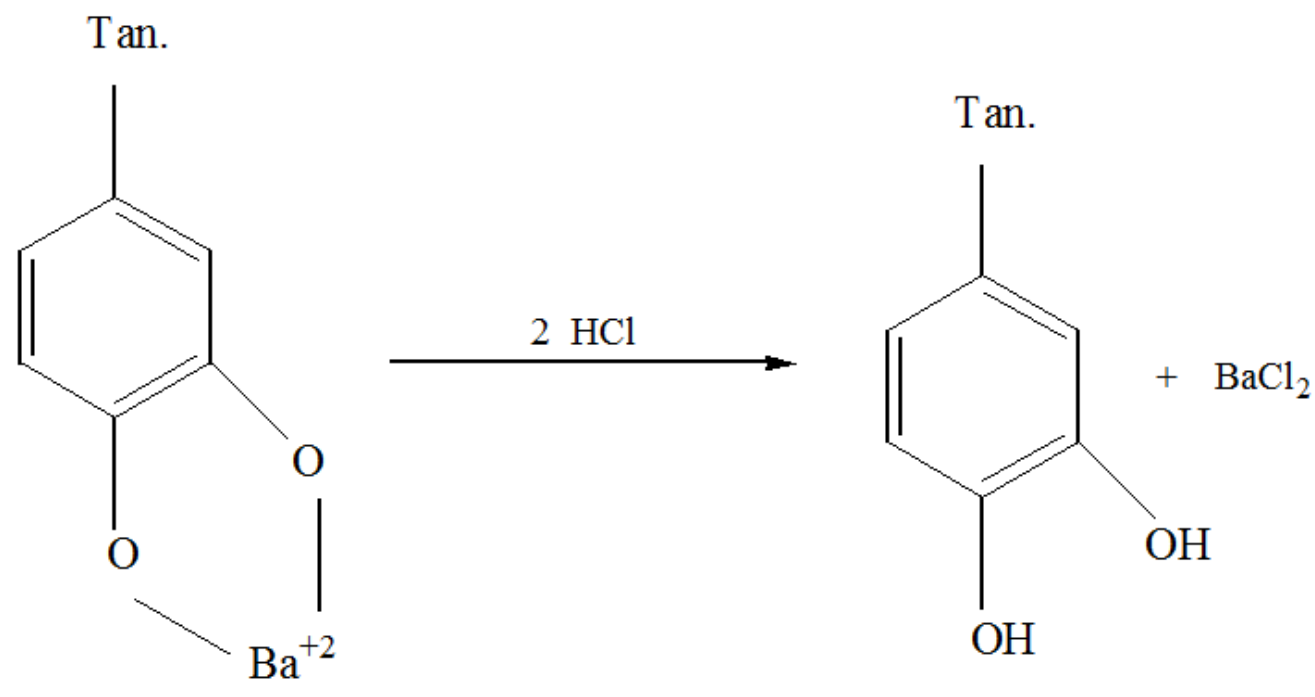

Fig. 6. Release of $\mathrm{Ba}$ from complex upon acidification during heating

As indicated in Fig. 5, some sample curves showed a slight increase in the weight percent. This behavior is attributed to the oxidation reaction of PVC by $\mathrm{O}_{2}$ (of air), but it was not found in the $0.5 \%$ sample. This was because the degradation reaction during preparation of sample involves both the decomposition reactions and oxidation reaction. It follows that the oxidation reaction may reach to its end or that degradation reactions were faster than the oxidation reactions. Generally, this behavior agrees with the action of barium-tannate, as well as tannin that is generated during thermal stabilization action (eq.1), as an active thermal stabilizer system. 


\section{CONCLUSIONS}

The results obtained in this study show that barium-tannin chelant can act as an active thermal stabilizer for PVC, where the infrared section of a series of PVC films with barium tannate were studied after thermal mixing and pressing. The results of this study showed the ability of this salt to improve the thermal stability of PVC, while the degradation rate of this polymer during monitoring the samples weight under thermal condition showed decreasing weight loss with increased level of this salt. Based on these results, barium tannate can act as a thermal stabilizer by scavenging of $\mathrm{HCl}$ with high performance.

\section{REFERENCES CITED}

Alfred, H. F., and Raymond, W. H. (1959). "The mechanism of poly(vinyl chloride) stabilization by barium, cadmium, and zinc carboxylates. Infrared studies,” $J$. Polym. Sci. 40, 419-431.

Ahmad, M., Nazli, S., and Anwar, M. M. (1989). "Studies on tannins from barks of Pinus roxburghi,” Jour. Chem. Soc. Pak. 11(3), 213-217.

Braun, D., and Bezdadea, E. (1986). "Theory of degradation and stabilization mechanisms,” In: Leonard I. Nass and Charles A. Heilberger (eds.), Encyclopedia of PVC , Vol.1 , Mercel Deckker Inc. , N.Y. and Basel, 397-429.

Chesworth, J. M., Stuchbury, T., and Scaife, J. R. (1998). An Introduction to Agricultural Biochemistry, Chapman and Hall, London, 55-58.

Kawamoto, H., Nakatsubo, F., and Murakami, K. (1996). "Stoichiometic studies of tannin-protein co-precipitation,” Phytochemistry 41(5), 1427-1431.

Kawamoto, H., Nakatsubo, F., and Murakami, K. (1995). "Quantitative determination of tannin and protein in the precipitates by high-performance liquid chromatograph,” Phytochemistry 40, 1503-1505.

Moayad, N., Khalaf, H. A., Shnawa, M. K., Goda, M. A., and Dia’a, A. A. (2007). "Phenolic antioxidant for polyolefins from grafted phenol on polyethylene wax," In: $8^{\text {th }}$ International Seminar on Polymer Science \& Technology , ISPST 2007 , October 2007, Tehran, Iran, SCP 3000.

Ollis, W. D. (1961). Recent Developments the Chemistry of Natural Phenolic Compounds, Pergamon Press, Oxford, 134-151.

Owen, E. D. (1984). Degradation and Stabilization of PVC, Elsevier Applied Science Puplishers Ltd., London, 21-252.

Rabek, J. F. (1970). Experimental Methods in Polymer Chemistry, John Wiley \& Sons, New York, pp: 221-253.

Yonede, S., and Nakatsubo, F. (1998). "Effect of the hydroxylation patterns and degrees of polymerization of condensed tannins on their metal - chelating capacity,” J. of Wood Chem. and Technol. 18(2), 193-205.

Article submitted: June 23, 2009; Peer review completed: Dec. 19, 2010; Revised version received: December 20, 2010; Accepted January 13, 2011; Published: January 15, 2011. 